@ERSpublications

Social support and complementary monetary incentives may add significant value to TB control programmes http://ow.ly/KPKji

Riccardo Alagna ${ }^{1}$, Mamadou Moussa Diaw ${ }^{2}$, Rosella Centis ${ }^{3}$, Daniela Maria Cirillo ${ }^{1}$ and Giorgio Besozzi ${ }^{4}$

${ }^{1}$ TB Supranational Reference Laboratory, IRCCS San Raffaele Scientific Institute, Milan, Italy. ${ }^{2}$ District Sanitaire de Diofior/Département de Fatick, Dioffior, Senegal. ${ }^{3}$ WHO Collaborating Centre for Tuberculosis and Lung Diseases, Fondazione S. Maugeri, IRCCS, Tradate, Italy. ${ }^{4}$ StopTB Italia, Milan, Italy.

Correspondence: Riccardo Alagna, TB Supranational Reference Laboratory, IRCCS San Raffaele Scientific Institute, Milan, Italy. E-mail: alagna.riccardo@hsr.it

Received: Jan 192015 | Accepted after revision: March 142015 | First published online: April 162015

Support statement: This project was funded by Fondazione Italo Monzino (Milan, Italy).

Conflict of interest: None declared.

\title{
References
}

1 Sotgiu G, Mauch V, Migliori GB, et al. Evidence-based, agreed-upon health priorities to remedy the tuberculosis patient's economic disaster. Eur Respir J 2014; 43: 1563-1566.

2 Lönnroth K, Migliori GB, Abubakar I, et al. Towards tuberculosis elimination: an action framework for low-incidence countries. Eur Respir J 2015; 45: 928-952.

3 Falzon D, Zellweger JP, Migliori GB, et al. Drug resistance and tuberculosis elimination in low-incidence countries. Eur Respir J 2014; 44: 1408-1411.

4 Tanimura T, Jaramillo E, Weil D, et al. Financial burden for tuberculosis patients in low- and middle-income countries: a systematic review. Eur Respir J 2014; 43: 1763-1775.

5 Sixty-seventh World Health Assembly. Resolution WHA67.1. Global strategy and targets for tuberculosis prevention, care and control after 2015. Geneva, World Health Organization, 2014. http://apps.who.int/gb/ebwha/ pdf_files/WHA67/A67_R1-en.pdf

6 Institute of Medicine (US) Forum on Microbial Threats. Knobler S, Mahmoud A, Lemon S, et al., eds. The Impact of Globalization on Infectious Disease Emergence and Control. Exploring the Consequences and Opportunities. Workshop Summary. Washington, National Academies Press (US), 2006.

7 Dara M, de Colombani P, Petrova-Benedict R, et al. Minimum package for cross-border TB control and care in the WHO European region: a Wolfheze consensus statement. Eur Respir J 2012; 40: 1081-1090.

8 Esposito S, D’Ambrosio L, Tadolini M, et al. ERS/WHO Tuberculosis Consilium assistance with extensively drug-resistant tuberculosis management in a child: case study of compassionate delamanid use. Eur Respir J 2014; 44: $811-815$

9 Codecasa LR, Ciconali G, Mazzola E, et al. Managing an extensively drug-resistant tuberculosis outbreak: the public health face of the medal. Eur Respir J 2015; 45: 292-294.

10 World Health Organization. Global tuberculosis report 2014. WHO/HTM/TB/2014.08. Geneva, World Health Organization, 2014.

11 Groupe Consultatif pour le Sénégal. Senegal Poverty, Inequality and Gender: an Overview. Poverty Note GC2014-012. 2014. www.gcsenegal.gouv.sn/docs/GC2014-012\%20Poverty\%20Note\%20\%201_Overview_final\% 20Englishn.pdf

12 Diel R, Loddenkemper R, Zellweger JP, et al. Old ideas to innovate tuberculosis control: preventive treatment to achieve elimination. Eur Respir J 2013; 42: 785-801.

\section{Video directly observed therapy for treatment of tuberculosis is patient- oriented and cost-effective}

To the Editor:

Curing tuberculosis (TB) entails adhering to a multidrug regimen for $\geqslant 6$ months [1]. Failure to take the medications as prescribed can lead to treatment failure, drug resistance and further spread of TB, resulting in morbidity and death for the patient and a threat to public health. Treatment failure is the most important cause of drug-resistant TB, which is much more long, expensive and toxic to treat, and the outcomes of which are still unsatisfactory [2-4]. The public health consequences of nonadherence to TB treatment led to 
directly observed therapy (DOT) becoming the universal standard of care [5-8]. While DOT is a best practice model for TB treatment, it is labour intensive and can itself be a barrier to effective therapy because of its inconvenience for patients. The expense may be prohibitive for cash-strapped public healthcare systems [9].

"Telehealth", or the delivery of healthcare services at a distance with information and communications technology, has the potential to overcome deficiencies of direct healthcare delivery. Applying home-phone video for real-time DOT of $\mathrm{TB}$ has been reported to be practical in two pilot studies [10, 11]. The objective of this study was to assess the acceptability and cost-effectiveness of real-time video-DOT (V-DOT) on mobile devices as an alternative to in-person DOT for administration of TB medication.

With the approval of Illinois Department of Public Health, DuPage County piloted a V-DOT programme using Skype (Microsoft, Redmond, WA, USA) in January 2013 as an adjunct to the existing in-person DOT programme. In this study, we retrospectively reviewed data from subjects who underwent V-DOT at our DuPage County Health Department Tuberculosis Clinic (Wheaton, IL, USA). The clinic treated 68 adults for active TB from January 2013 to December 2014. Age, sex and treatment duration were collected by chart review of medical records using standardised abstraction forms and pre-established definitions. Inclusion criteria for being on V-DOT were age $>18$ years, availability of electronic devices, and availability of a member of staff who could speak the patient's language and provide appropriate confidentiality. Patients diagnosed with multidrug-resistant TB or who were considered at risk of poor adherence (the homeless, HIV patients or those who were not being truthful) were not offered V-DOT.

We did not provide any equipment to the patients. They used their own smartphones or personal computers. Skype is free software and our nursing staff spent about an hour for training each patient.

Each V-DOT session consisted of six steps with an average duration $\sim 5$ min. Figure 1a illustrates the $\mathrm{V}$-DOT process. We evaluated the experience by a multiple-choice questionnaire. The questionnaire was mailed to the patients and responses were voluntary (fig. 1b). Adherence of patients to V-DOT was measured by compliance to treatment and responses to the questionnaire.

Expense calculations included the mileage cost of the distance between the TB clinic and the patients' addresses, and the staff's time. The patients' time and lost wages of standard DOT could not be calculated because of the heterogeneity of the patients.

68 patients with active TB were treated in our clinic from January 2013 through December 2014. 20 patients met the V-DOT inclusion criteria and 11 consented to be in the V-DOT programme. Out of 11 subjects, six were females and five were males, and age ranged from 19 to 64 years old. Three subjects were born in the Philippines, three in India, and one in each Korea, Mexico and Myanmar. Two subjects were US-born. Nine subjects spoke English, one Hindi and one Spanish. Six of the patients were college students or graduates and the rest were under diploma. Nine subjects used smartphones and two used personal computers at home for V-DOT. 11 successfully completed treatment with cure outcomes; 1083 V-DOT observations were performed with a $97 \%$ compliance rate.

The total cost savings for mileage was US\$7583.00. The average savings of miles driven for each patient was 9499 miles $(15287 \mathrm{~km})$. Approximately $579 \mathrm{~h}$, valued at US $\$ 144750$ in human resource costs and travel expenses of staff travel time, was saved. The incalculable costs to the patients are additional savings.

Out of 11 patients, eight patients participated in the voluntary questionnaire. Patient experience included that seven (88\%) out 11 patients were well satisfied with V-DOT, and all respondents (100\%) considered V-DOT an improvement over to the traditional DOT and strongly recommended it to other TB patients (fig. 1b).

The current study showed that V-DOT is a patient-oriented and cost-effective method that could be useful in a variety of TB treatment settings for a select group of patients. The drawbacks of conventional DOT not only include cost and staff time, but the fixed-time commitments detract from a patient-centred approach [12]. For example, a patient experiencing nausea may do better if the drugs are given at night or with food, but the more regimented DOT is not as flexible as V-DOT. An advantage of DOT is patient interaction and the ability to reinforce commitment to therapy, but these can also be employed with V-DOT.

Several other studies have sought to explore the role of technology in facilitating patient interaction, reinforcing behaviour and improving adherence. A study conducted in South Australia used home video observation as a patient-centred, resource-efficient way of delivering direct observation for TB, which was found to be cost-effective when compared with a drive-around service [13]. KRUEGER et al. [10] demonstrated that videophone observation of medication ingestion was a cost-effective and reliable method, while significantly saving travel costs and staff salaries of almost US\$140000. Our small study showed an equally impressive saving in travel and human resource costs. The high rate of V-DOT adherence compared favourably to our historic adherence rates. 
a)

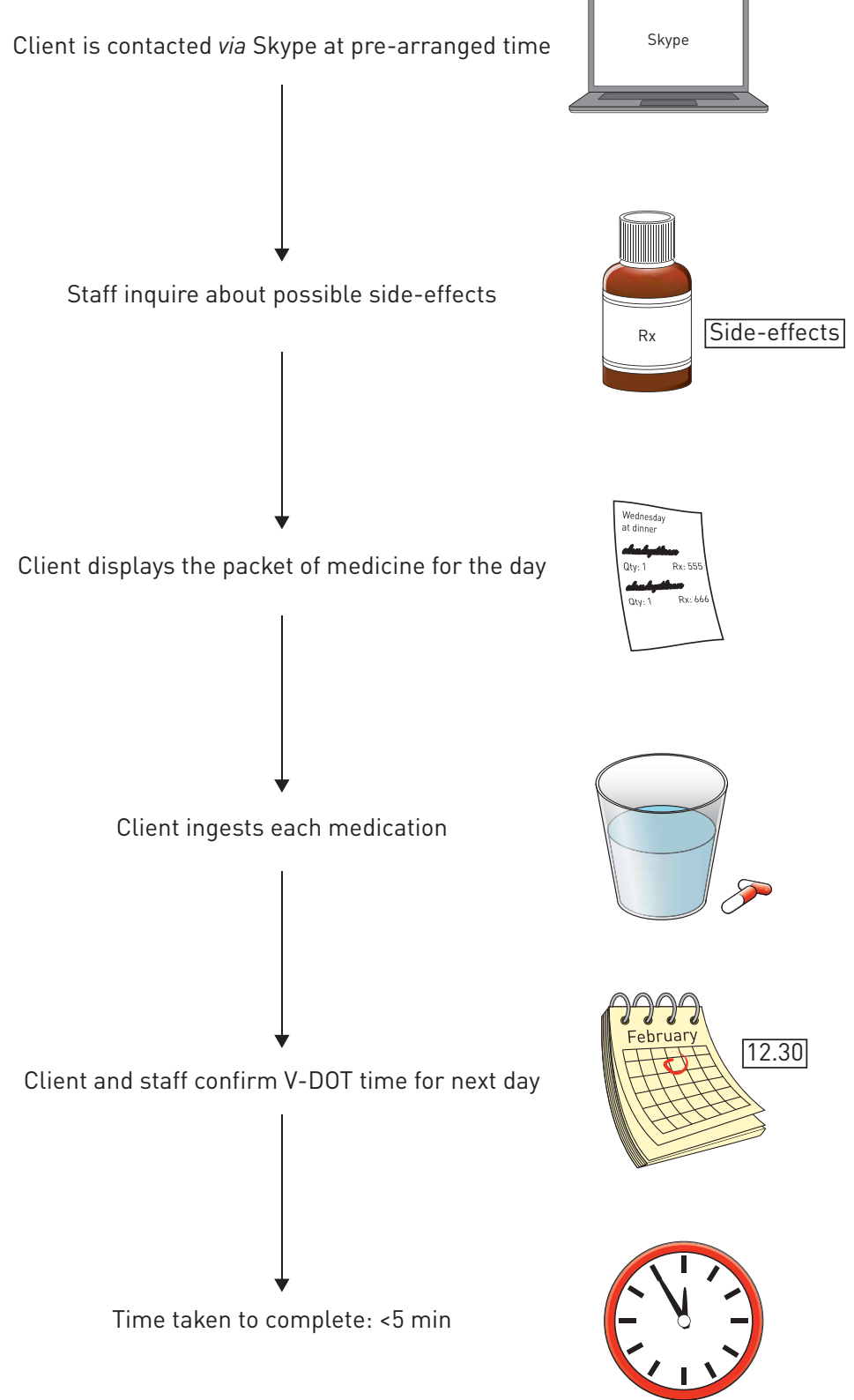

b)

\begin{tabular}{|c|c|}
\hline Question & Patients $\%$ \\
\hline \multicolumn{2}{|c|}{$\begin{array}{l}\text { How long have you been using V-DOT through } \\
\text { Skype? }\end{array}$} \\
\hline $2-4$ months & 64 \\
\hline 4-6 months & 12 \\
\hline $6-8$ months & 24 \\
\hline \multicolumn{2}{|c|}{$\begin{array}{l}\text { How long were you on DOT at home/work before } \\
\text { starting V-DOT through Skype? }\end{array}$} \\
\hline $1-2$ months & 76 \\
\hline $2-4$ months & 12 \\
\hline$>6$ months & 12 \\
\hline \multicolumn{2}{|c|}{ How convenient are the V-DOT appointments? } \\
\hline Excellent & 88 \\
\hline Good & 12 \\
\hline \multicolumn{2}{|c|}{$\begin{array}{l}\text { If you were on DOT before, how convenient were } \\
\text { the DOT visits? }\end{array}$} \\
\hline Excellent & 76 \\
\hline Good & 12 \\
\hline Fair & 12 \\
\hline
\end{tabular}

How hard was it to set up and access Skype on your computer?

$\begin{array}{ll}\text { Very easy } & 88 \\ \text { Easy } & 12\end{array}$

How easy was it to establish a convenient time for V-DOT?

Very easy
Easy

Do you feel that V-DOT saves you time?

Yes

Do you feel that V-DOT protects your confidentiality?

Yes

How easy has it been to utilise the V-DOT system and staff?

$\begin{array}{ll}\text { Excellent } & 88 \\ \text { Good } & 12\end{array}$

How would you rate your overall satisfaction with V-DOT?

$\begin{array}{ll}\text { Excellent } & 88 \\ \text { Good } & 12\end{array}$

Do you feel that V-DOT is an improvement over traditional DOT?

Yes

Would you recomend V-DOT to another patient? Yes

FIGURE 1 a) Video directly observed therapy (V-DOT) process and b) results of the survey on the patients using it. DOT: directly observed therapy.

However, a main positive outcome is that V-DOT is more patient friendly. It can be more flexible in time and allow greater freedom for the patient, saving them time and travel expense, which cannot be translated into monetary savings. The V-DOT increase in patient-oriented TB treatment may improves compliance and lower stigma for TB patients.

The limitation of V-DOT is that this approach may not apply to all patients in all settings: the Internet technology may not be available; patients may not be technologically savvy enough to use an Internet-based video system; patients may not have a permanent home; and it may be challenging in vulnerable populations. Another concern of V-DOT is privacy; transmitting protected health information through the Internet has the potential to be compromised, even with encryption software. Other limitations are the relative small sample size, lack of controls and the failure to control for biases. As with all interventions, it is the responsibility of healthcare professionals to weigh the risks of V-DOT with the benefits, which may vary across healthcare settings.

This study shows that a video-based approach using mobile devices provides meaningful direct observation for TB patients, which is associated with high compliance and fewer healthcare resources. V-DOT fully fits 
the vision of TB Elimination, which recently developed recommendations on how to reach it [14, 15]. Larger trials should be conducted to establish the role of V-DOT in other TB care settings. V-DOT could be important in other diseases requiring long treatment regimens, such as HIV/AIDS and viral hepatitis.

@ERSpublications

A video-based approach is a novel, patient-oriented strategy for TB treatment http://ow.ly/JDQCi

Mehdi Mirsaeidi ${ }^{1,2}$, Maham Farshidpour ${ }^{2}$, Deborah Banks-Tripp ${ }^{1}$, Sarah Hashmi ${ }^{1}$, Carrie Kujoth ${ }^{1}$ and
Dean Schraufnagel

${ }^{1}$ DuPage County Health Department, Wheaton, IL, USA. ${ }^{2}$ University of Illinois at Chicago, Chicago, IL, USA.

Correspondence: Mehdi Mirsaeidi, Division of Pulmonary, Critical Care, Sleep, and Allergy, Department of Medicine M/C 719, University of Illinois at Chicago, 840 S. Wood St, Chicago, IL 60612-7323, USA. E-mail: mmirsae@uic.edu

Received: Jan 212015 | Accepted after revision: Feb 212015 | First published online: March 182015

Conflict of interest: Disclosures can be found alongside the online version of this article at erj.ersjournals.com

Support Statement: Mehdi Mirsaeidi is supported by US National Institutes of Health grant 5 T32 HL 82547-7. The funder had no role in study design, data collection and analysis, decision to publish, or preparation of the manuscript. Funding information for this article has been deposited with FundRef.

Acknowledgement: The authors would like to thank Golnaz Ebrahimi (University of Illinois at Chicago, Chicago, IL, USA) and Marybeth Allen (University of Louisville, Louisville, KY, USA) for their editorial assistance.

\section{References}

TB CARE I. International Standards for Tuberculosis Care, Edition 3. The Hague, TB CARE I; 2014.

Gandhi NR, Nunn P, Dheda K, et al. Multidrug-resistant and extensively drug-resistant tuberculosis: a threat to global control of tuberculosis. Lancet 2010; 375: 1830-1843.

3 Falzon D, Gandhi N, Migliori GB, et al. Resistance to fluoroquinolones and second-line injectable drugs: impact on multidrug-resistant TB outcomes. Eur Respir J 2013; 42: 156-168.

4 Migliori GB, Sotgiu G, Gandhi NR, et al. Drug resistance beyond extensively drug-resistant tuberculosis: individual patient data meta-analysis. Eur Respir J 2013; 42: 169-179.

5 Chaulk CP, Kazandjian VA. Directly observed therapy for treatment completion of pulmonary tuberculosis: Consensus Statement of the Public Health Tuberculosis Guidelines Panel. JAMA 1998; 279: 943-948.

6 Frieden TR, Sbarbaro JA. Promoting adherence to treatment for tuberculosis: the importance of direct observation. World Hosp Health Serv 2007; 43: 30-33.

7 Migliori GB, Zellweger JP, Abubakar I, et al. European union standards for tuberculosis care. Eur Respir J 2012; 39: 807-819.

8 van der Werf MJ, Sandgren A, D'Ambrosio L, et al. The European Union standards for tuberculosis care: do they need an update? Eur Respir J 2014; 43: 933-942.

9 Belknap R, Weis S, Brookens A, et al. Feasibility of an ingestible sensor-based system for monitoring adherence to tuberculosis therapy. PLoS One 2013; 8: e53373.

10 Krueger K, Ruby D, Cooley P, et al. Videophone utilization as an alternative to directly observed therapy for tuberculosis. Int J Tuberc Lung Dis 2010; 14: 779-781.

11 DeMaio J, Schwartz L, Cooley P, et al. The application of telemedicine technology to a directly observed therapy program for tuberculosis: a pilot project. Clin Infect Dis 2001; 33: 2082-2084.

12 Noyes J, Popay J. Directly observed therapy and tuberculosis: how can a systematic review of qualitative research contribute to improving services? A qualitative meta-synthesis. J Adv Nurs 2007; 57: 227-243.

13 Wade VA, Karnon J, Eliott JA, et al. Home videophones improve direct observation in tuberculosis treatment: a mixed methods evaluation. PLoS One 2012; 7: e50155.

14 Diel R, Loddenkemper R, Zellweger JP, et al. Old ideas to innovate tuberculosis control: preventive treatment to achieve elimination. Eur Respir J 2013; 42: 785-801.

15 Lönnroth K, Migliori GB, Abubakar I, et al. Towards tuberculosis elimination: an action framework for low-incidence countries. Eur Respir J 2015; 45: 928-952. 